\title{
O ensaio fílmico como encontro entre o sujeito e o mundo por
} meio do cinema

Gabriela Machado Ramos de Almeida ${ }^{1}$

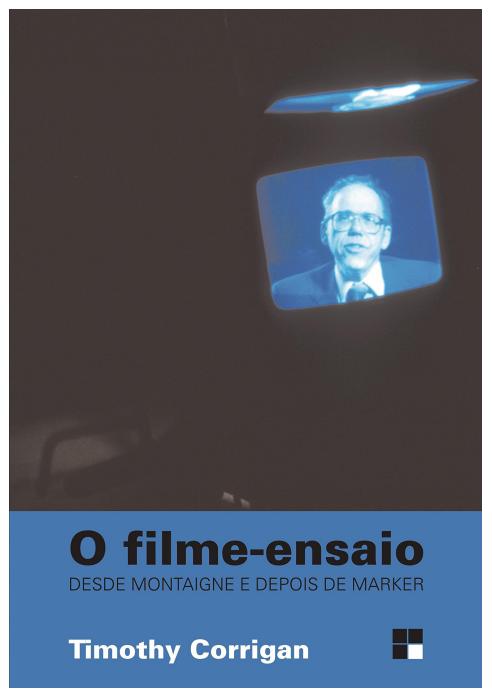

\section{Resenha}

CORRIGAN, Timothy. O filme-ensaio: desde Montaigne e depois de Marker. Campinas: Papirus, 2015.

1 Doutora em Comunicação e Informação pela Universidade Federal do Rio Grande do Sul (UFRGS), com período de doutorado sanduíche na Universitat Autònoma de Barcelona (UAB), sob supervisão de Josep Maria Català. Mestre em Comunicação e Cultura Contemporâneas pela Universidade Federal da Bahia (UFBA). Professora do curso de Comunicação Social da Universidade Luterana do Brasil (ULBRA), em

Canoas/RS. Autora do livro O ensaio fílmico ou o cinema à deriva (Ed. Alameda, 
O ensaio, desde as suas origens na literatura, costuma ser categorizado como a mais livre, a mais fugidia das formas de reflexão. Não propõe respostas acabadas, mas a inquietação, a abertura, a dúvida. Em função de características imanentes que parecem inviabilizar a sua categorização como um gênero narrativo em sentido estrito, o ensaio costuma ser definido a partir de negativas ou de um entendimento frouxo de que se trata de uma forma expressiva em que tudo vale ou, principalmente, que carece de rigor.

Embora seja possível identificar um devir-ensaio no cinema desde as suas primeiras décadas e nas Teorias do Cinema pelo menos a partir de 1948, com Alexandre Astruc ${ }^{2}$, é sobretudo nos últimos vinte anos que ganha força a produção de ensaios fílmicos, no seio do que se pode caracterizar como uma virada subjetiva do documentário. Embora, também, o filme-ensaio não seja necessariamente um braço do documentário, a sua vinculação ao cinema de não-ficção acabou tornando esse tipo de produção objeto de interesse prioritário de pesquisadores do documentário no Brasil.

É possível que o artigo O filme-ensaio, de Arlindo Machado (2003), seja o primeiro texto publicado por um autor brasileiro a tentar sistematizar algum conhecimento a respeito de um cinema de traços ensaísticos que se caracterizaria principalmente pelo desejo de produzir pensamento, mas foi apenas 12 anos depois que os dois primeiros livros inteiramente dedicados ao tema foram lançados no Brasil: O ensaio no cinema: formação de um quarto domínio das imagens na cultura audiovisual contemporânea, coletânea de artigos organizada por Francisco Elinaldo Teixeira, e O filme-ensaio: desde Montaigne e depois de Marker, tradução para o português do livro de Timothy Corrigan publicado originalmente em 2011. Essas breves indicações revelam o quão recente é a constituição de uma fortuna crítica mais consistente em torno do ensaio fílmico no país.

\footnotetext{
${ }^{2}$ No seminal texto Naissance d'une nouvelle avant-garde: la caméra-stylo, em que Astruc se refere a uma qualidade dialética do cinema, espécie de mecanismo relacional entre diversos saberes, e no qual afirma que, ao se tornar uma linguagem, o cinema pode expressar pensamentos tal qual o ensaio e o romance. Astrux chega a dizer que, se Descartes tivesse que escrever o Discurso do Método na década de 1940, o faria com uma câmera $16 \mathrm{~mm}$ e filme.
} 
O livro de Corrigan parte de duas premissas principais: a primeira é de que cabe ao ensaio fílmico um lugar de autonomia em relação ao documentário e ao cinema experimental, para que a prática seja situada "em um lugar histórico mais refinado, que faça justiça às suas percepções e interações distintas” (CORRIGAN, 2015, p. 9). Isso significa, para o autor, que as tentativas de pensar o ensaio fílmico inserido na historiografia do cinema limitam as possibilidades de reconhecimento do fenômeno em toda a sua capacidade de intervenção crítica. A segunda é de que o filme-ensaio "focaliza questões centrais na relação historicamente variada e multidimensional entre o cinema e a literatura" (CORRIGAN, 2015, p. 10), nos convidando a pensar esse vínculo a partir de outros parâmetros que não sejam as interações entre o cinema e a ficção narrativa, o teatro dramático ou a poesia, e buscando privilegiar especialmente a relação entre verbal e visual e não aspectos como a adaptação.

Interessa a Corrigan considerar a inflexão ensaística no cinema e através do cinema, tomando o ensaístico como um encontro entre o eu e o domínio público. Assim, o filme-ensaio pode ser pensado como linguagem que mobiliza diversas matérias expressivas e traz ao primeiro plano uma voz reconhecível, uma expressão pessoal. No entanto, mesmo que essa expressão pessoal eventualmente assuma um tom autobiográfico, ela não é confessional, uma vez que o ensaio pressupõe a manifestação de um sujeito que se coloca em abertura para o mundo, numa espécie de ação performativa do eu, caracterizando-se como "prática que renegocia pressupostos a respeito da objetividade documentária, da epistemologia narrativa e da expressividade autoral dentro do contexto determinante da heterogeneidade instável de tempo e lugar." (CORRIGAN, 2015, p. 10).

O livro O filme-ensaio: desde Montaigne e depois de Marker é estruturado em duas partes: a primeira, intitulada Rumo ao filme-ensaio e composta por dois capítulos, busca definir o fenômeno e construir para ele uma historiografia própria. A segunda, chamada de Modos ensaísticos, mapeia em uma tipologia os cinco os grandes modos que, para Corrigan, agrupam de alguma forma os filmes-ensaio.

$\mathrm{Na}$ parte um, o autor discorre sobre a configuração do filme-ensaio a partir da tradição literária, buscando suas origens em Michel de Montaigne, bem como situa 
nas tradições do documentário e do cinema de vanguarda a emergência história do ensaísmo no cinema. Timothy Corrigan afirma o ensaístico como a modulação entre um ponto de vista pessoal e uma experiência pública, expostos numa condição constantemente provisória e exploratória (daí a razão de o termo "ensaio" remeter frequentemente a "tentativa" ou "teste"). Nesse sentido, o ensaístico promove deslocamentos em relação à noção romântica de autoria que o campo do cinema por vezes incorpora, ao desestabilizar o sujeito autoral, a própria obra e sua apreensão pelo leitor/espectador.

A passagem entre o ensaio literário e o filme-ensaio estaria situada no ensaio fotográfico, pelo modo como promove uma tensão dialógica entre o verbal e 0 visual (a exemplo da colaboração entre James Agee e Walker Evans na série Elogiemos os homens ilustres, de 1939). No caso do cinema, Corrigan vai se centrar, nessa primeira parte do livro, na tradição francesa, especialmente em Agnès Varda, Alain Resnais e Marker, cuja obra é assentada com mais ênfase com bases literárias.

A parte dois é uma tipologia dividida em cinco capítulos, dedicados aos chamados modos ensaísticos:

1) filme-ensaio como entre-vista: abarca os retratos e autorretratos que possuem inflexão ensaística, com o devido cuidado de não considerar todos os filmes-ensaio biográficos ou autobiográficos e, na via oposta, também não considerar qualquer filme biográfico ou autobiográfico como ensaio;

2) as excursões cinematográficas como viagem ensaística: centradas nas experiências de viagem, caminhada ou exploração, considera que os encontros experienciais com os espaços do mundo permitem a um sujeito investigar-se e transformar-se;

3) os diários ensaísticos ou velocidades cinematográficas da vida pública: dizem respeito à recuperação da escritura diarística pelos filmes-ensaio e à dramatização de "uma temporalidade ensaística que diz respeito essencialmente ao timing do pensamento como figura ativa da subjetividade pública." (CORRIGAN, 2015, p. 132);

4) atualidade dos acontecimentos ou o filme ensaio como editorial: de teor social 
e político, refere-se a filmes-ensaio que operam como investigações sobre a verdade e a ética de acontecimentos e comportamentos contemporâneos, designando formas de compreender e reagir pessoal ou publicamente às notícias cotidianas. Diferentemente de documentários investigativos, para Corrigan os filmes-ensaio editoriais "revelam e analisam não apenas as realidades e os fatos que são documentados, mas também as agências subjetivas (emaranhadas nos filmes e na sua recepção) dessas realidades e desses fatos." (CORRIGAN, 2015, p. 154);

5) por fim, o cinema refrativo: diz respeito ao caráter autorreflexivo de uma expressiva parcela dos filmes-ensaio, que criam seus próprios dispositivos e princípios estéticos e fazem deles um uso crítico, produzindo com esses processos uma reflexão de teor metalinguístico sobre o cinema. É o que ocorre, para usar a mesma expressão do autor, quando filmes interrogam filmes.

Para Corrigan, parte da força do ensaio estaria, assim, na sua capacidade de questionar ou redefinir pressupostos representacionais e abraçar a sua própria condição antiestética, ao mesmo tempo em que os desafios para definir o filmeensaio são os motivos mesmos que o tornam tão inventivo:

A meio caminho da ficção e da não-ficção, das reportagens jornalísticas e da autobiografia confessional, dos documentários e do cinema experimental, eles são, primeiro, práticas que desfazem e refazem a forma cinematográfica, perspectivas visuais, geografias públicas, organizações temporais e noções de verdade e juízo na complexidade da experiência. (CORRIGAN, 2015, p. 9-10).

Buscar um lugar histórico mais refinado para os filmes-ensaio significa para Timothy Corrigan, portanto, situar-se em lugares escorregadios, entre a tentativa de categorização e o cuidado com a natureza antigenérica própria desta forma de expressão; entre o rigor em busca de uma definição e o caráter de "método não metódico" daquilo a que o autor se refere como um "gênero de experiência". Escrever sobre o ensaísmo e os filmes-ensaio exigiria mais autoconsciência do que de costume na escrita acadêmica e histórica e o caminho trilhado pelo autor passa por assumir que o filme-ensaio opera com sobreposições múltiplas, diversas e inevitáveis, ou seja, que existem especificidades textuais dos filmes que atestam 
